\title{
RV dyssynchrony in PAH as evidenced by slice to slice minimum volume timing
}

\author{
Qiao Han ${ }^{1 *}$, Stephan Philip Leonhardt Altmayer ${ }^{1}$, Amit R Patel ${ }^{2}$, Karima Addetia ${ }^{2}$, Yuchi Han ${ }^{1}$ \\ From 18th Annual SCMR Scientific Sessions \\ Nice, France. 4-7 February 2015
}

\begin{abstract}
Background
Pulmonary hypertension has been associated with right ventricular (RV) dyssynchrony. In patients with left side heart failure, treating left ventricular dyssynchrony has been shown to improve patient outcome. Previous studies have demonstrated that RV dyssynchrony was associated with RV dilation, interventricular septum diastolic flatterning and eccentric hypertrophy. We propose simple parameters from cine MRI that can potentially help quantify the complex movements without using special sequences or algorithms.
\end{abstract}

\section{Methods}

\section{Study population}

Four healthy subjects ( 2 females and 2 males) and 11 pulmonary arterial hypertension (PAH) patients (10 females and 1 male) were included in the study. Two patients had QRS duration of $>120 \mathrm{~ms}$.

\section{CMR imaging}

The study population underwent cardiac MRI exams on $1.5 \mathrm{~T}$ units (Avanto Siemens, Erlangen, Germany or Phillips Achieva, Best, Netherlands). Cine short axis data were obtained using steady state free procession imaging with voxel size $1.67 \times 1.67 \mathrm{~mm}$, repetition time $29.4 \mathrm{~ms}$, echo time $1.19 \mathrm{~ms}$ for the Siemens unit, and voxel size $1.42 \times 1.42 \mathrm{~mm}$, repetition time $2.49 \mathrm{~ms}$, echo time $1.25 \mathrm{~ms}$ for the Phillips unit.

\section{CMR analysis}

Short axis cine and RVOT images were imported into QMass (Medis, Laiden, the Netherlands). Endocardial contours were manually traced in all phases for the RV in QMass. Trabeculation was included in the contours,

${ }^{1}$ Cardiology, University of Pennsylvania, Philadelphia, PA, USA

Full list of author information is available at the end of the article and RV structural information was subsequently calculated.

\section{Dyssynchrony}

For each ventricle, we identified the global min volume phases, the min volume phase for each slice, and converted phase numbers into exact timing. We denoted the two timings as $t_{0}, t_{i}$ respectively. We calculated two parameters to describe the levels of dyssynchrony present in different subjects: $T_{\text {DEVslices_MinV }}$, the deviation of $\left\{t_{i}\right\}$ from $t_{0}$, and $T_{\text {SDslices }}$, the standard deviation of $\left\{t_{i}\right\}$.

\section{Results}

The average LV ejection fraction (EF) for healthy subjects was $67.0 \pm 4.0 \%$, and $60.3 \pm 6.5 \%$ for PAH patients. The average RVEF for healthy subjects was $54.5 \pm 6.7 \%$, and $38.5 \pm 12.7 \%$ for PAH patients. RV septal wall bounce was observed in majority of our patient population. In the quantitative assessments for LV, RV, and two ventricles combined, PAH patients showed higher variation in the timing of contraction among individual slice positions as well as higher deviation from the minimal RV volume phase ( $\left.\mathrm{T}_{\mathrm{DEV} \text { slices_MinV }}\right)$ (Figure 1$)$. Normal range of $\mathrm{T}_{\text {DEVslices_MinV }}$ for the RV is $34-52 \mathrm{~ms}$ and a subpopulation of the $\mathrm{PAH}$ population falls into this range. Other PAH patients have "dyssynchrony", including the two patients with prolonged QRS. The RV dyssynchrony parameters showed moderate correlations with RVEF (Figure 2).

\section{Conclusions}

$\mathrm{RV}$ function is an important clinical measurement especially in the prognosis of pulmonary hypertension. We proposed simple parameters $\mathrm{T}_{\mathrm{SDslices}}$ and $\mathrm{T}_{\mathrm{DEV} \text { slices_MinV }}$ derived from cine CMR to describe RV dyssynchrony in PAH patients. 


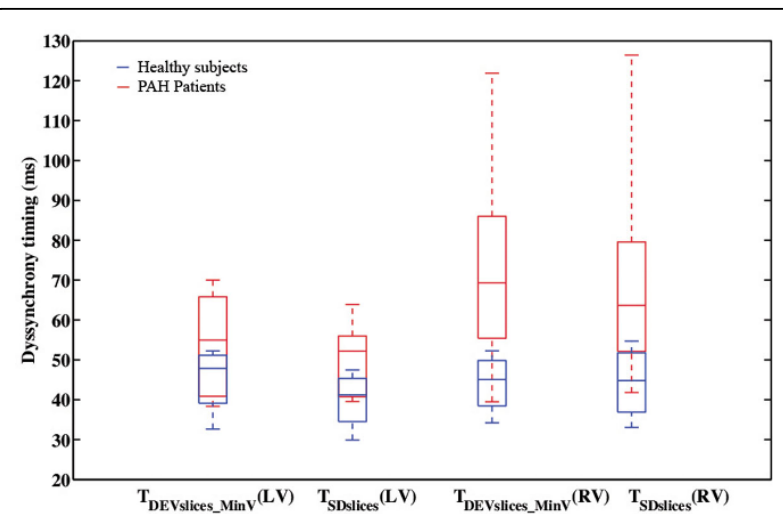

Figure $1 \mathrm{LV}$ and RV Dyssynchrony evidenced by slice to minimal volume timing.

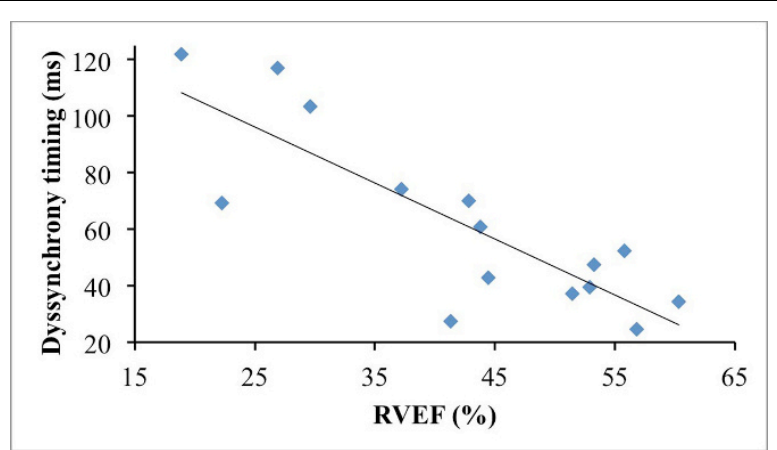

Figure $2 T_{\text {DEVslices_MinV }}(R V)$ showed moderate correlation with RVEF $(y=-1.97 x+145.41, R 2=0.61)$.

\section{Funding}

CMREF: cardiovascular medical research and education fund.

\section{Authors' details}

${ }^{1}$ Cardiology, University of Pennsylvania, Philadelphia, PA, USA. ${ }^{2}$ Radiology, The University of Chicago Medicine, Chicago, IL, USA.

Published: 3 February 2015

doi:10.1186/1532-429X-17-S1-P170

Cite this article as: Han et al:: RV dyssynchrony in PAH as evidenced by slice to slice minimum volume timing. Journal of Cardiovascular Magnetic Resonance 2015 17(Suppl 1):P170.

\section{Submit your next manuscript to BioMed Central} and take full advantage of:

- Convenient online submission

- Thorough peer review

- No space constraints or color figure charges

- Immediate publication on acceptance

- Inclusion in PubMed, CAS, Scopus and Google Scholar

- Research which is freely available for redistribution

Submit your manuscript at www.biomedcentral.com/submit
C BioMed Central 